\title{
Effect of an Interventional Program on Diabetic Patients' Awareness Regarding Diabetic Retinopathy
}

\section{Hanaa S. Said 1*, Mona S. Hamed ${ }^{2}$}

${ }^{1}$ Department of Family Medicine, Faculty of Medicine, Zagazig University, Egypt.

${ }^{2}$ Department of community, environmental and occupational medicine, Faculty of Medicine, Zagazig University, Egypt.

\begin{abstract}
:
Background: Diabetic retinopathy is the commonest micro-vascular complication of diabetes and the leading cause of blindness in adults of working age mainly. Follow up is crucial to the effective management of diabetic retinopathy. Objectives: To Measure the percent of change in Knowledge, attitude, and practice about diabetic retinopathy after the interventional program and its frequency in Diabetic patients. Methods: An interventional study was conducted on 70 diabetic patients. The study was applied in the diabetes clinic at Zagazig University hospital. The studied patients were above 18 years of age and both types of diabetes. Patients were interviewed using Fahmy's questionnaire to assess the socio-demographic characters and a pre-designed questionnaire for knowledge, attitude, and practice evaluation. Results: The satisfactory knowledge of retinopathy constituted only $8.6 \%$ while positive attitude towards retinopathy was found in $35.7 \%$ and only 3 out of 70 patients $(4.3 \%)$ were had a good practice of diabetic retinopathy in the pre-intervention phase. The score of knowledge about Diabetes mellitus and diabetic retinopathy significantly increased by $116.58 \%$ after health education also there was a significant increase in a positive attitude and good practice after intervention by $45.5 \%$ and $230.7 \%$ respectively. Financial problem was a common barrier to compliance with periodic eye checkups. Conclusion: Health education still has the upper hand in spreading awareness and improving the patient's self-care in the form of a positive attitude and good practice regarding his disease.
\end{abstract}

Keywords: Blindness, Compliance, Diabetes, Knowledge, Patient Education

\section{Introduction:}

Diabetes mellitus constitutes one of the noncommunicable threats to public health all over the world. 457 million people worldwide have diabetes in 2015, ${ }^{(1)}$ more than 39 million people in the Middle East, and North Africa (MENA) Region; by 2045 this will rise to 67 million in the MENA region and 642 million worldwide. Around $10 \%$ of all people with diabetes have type 1 diabetes. ${ }^{(2)}$ Diabetes is a fast-growing health problem in Egypt with a significant impact on morbidity, mortality, and health care resources.

The prevalence of type 2 diabetes (T2D) in Egypt is around $15.6 \%$ of all adults aged 20 to 79 in $2015,{ }^{(3)}$ there were 8.222 .600 cases of diabetes in 2017. (2) Diabetic retinopathy (DR) is considered one of the commonest and severe complications of diabetes mellitus disease (DM) and considered the fifth leading cause of visual impairment and the fourth leading cause of blindness in the world. Loss of productivity, lowering the quality of life and more socioeconomic burden are potential consequences of DR. ${ }^{(4)}$

American diabetes association recommends that an initial dilated and comprehensive eye examination within 5 years after the onset of diabetes in type 1 and at the time of diabetes diagnosis in type 2 , then repeat this careful examination once a year. It also stresses the need to optimize glycemic and blood pressure control. $^{(5)}$ Early stages of (DR) have no visual problems, so lack of awareness regarding the

*Corresponding author: drhanasalah@yahoo.com

(c) (1) This article is an open access article distributed under the terms and conditions of the Creative Commons Attribution (CC BY) license (http://creativecommons.org/licenses/by/4.0/) 
disease may lead to fulminant clinical complication which is preventable or even can delay it. ${ }^{(6)}$

Raising awareness about (DR) in turn improves the compliance of the patients regarding continuous periodic clinical examination, so it could be early diagnosed and treated. Appropriate patient education and mass health education are needed to encourage those at risk to seek appropriate and timely care. ${ }^{(7)}$

The study aimed to Measure the percent of change in Knowledge, attitude, and practice about DR after the interventional program and the frequency of Diabetic retinopathy in Diabetic patients at the diabetes clinic, Zagazig University Hospitals.

The aim of the current study is to measure the percent of change in Knowledge, attitude, and practice about diabetic retinopathy after the interventional program and its frequency in Diabetic patients.

\section{Methods:}

Study design and sampling method: An interventional study (pre and post-test intervention) was conducted on 70 diabetic patients after calculating the sample with an online open Epi program at 95\% confidence interval with a mean of pre-test attitude score was $15.0 \pm 2.1$ and post-test was $16.2 \pm 1.4$. ${ }^{(4)}$

The study was applied in the diabetes clinic at Zagazig University hospital, which is the major governmental teaching university hospital in Sharkia governorate. The sample units collected by systematic random technique (diabetic patients \{type 1 or 2 \} attending diabetes clinic asking for medical advice. The practical part of the study completed by attending the clinic for 3 hours/ day, 2 days/ week for 1 month.

\section{Study participants and data collection:}

Inclusion criteria: Diabetic patients older than 18 years of age and could give informed consent, both types of diabetes, any residence, and had diabetic retinopathy or not attending the diabetes clinic.

Exclusion criteria: Non-diabetic patients even had retinopathy for any other cause rather than diabetes and Patients younger than 18 years old were excluded.

Patients interviewed using Fahmy et al., $2015^{(8)}$ questionnaire to assess their sociodemographic characteristics including (mother and father education and occupation, sewage disposal, income, ........).

A structured interview questionnaire guided by (Srinivasan et al., $2017^{(6)}$ - Khalaf, $2019^{(4)}$ ) was used to assess the knowledge (which parts of the body affected with diabetes?, What are the symptoms of diabetic retinopathy, How were you diagnosed with DR and when?, what are the factors that worsening DR?, ......), attitude (Even if I forget to take my medicines on some days it is alright, I should go for a regular eye checkup as my doctor says, even if my sugars are under good control complications will occur, ......) and practice (Do you take medicines for diabetes as advised by the physician?, Do you go for regular eye follow up as advised by your physician?, how often do you 
go for a dilated eye checkup, why have you not gone for a periodic eye checkup regarding diabetic retinopathy to all patients included in the study.

The questionnaire toke about 20 minutes to be filled in each time. Patient education individual sessions or in small groups were applied and another previously scheduled two health education sessions to the other patients attending the clinic and not included in the study were done. Evaluation of the effect of health education done after 3 months post-education (telephone number and address of each patient were obtained to ensure communication). The practical part completed by attending the diabetes clinic for 2 days/week for 2 months.

a) Total scores for KAP were calculated by summing up the responses for each participant.

b) Eleven Knowledge questions were used, a score of 1 was given for each correct answer and a score of zero was given for an incorrect or "don't know" answers, total score of knowledge was 28 marks.

c) Five questions were used to assess practice, each correct answer to practice questions was awarded 1 mark while a wrong answer was given 0 marks, good practice was calculated if total practice score $\geq 4$.

d) The responses for patients' attitudes were based on a three-point scale (agree, uncertain, and disagree). Items were scored $(2,1$, and 0$)$ respectively; the score was reversed for negative statements, 4 questions were used, total mark $\geq 3$ was considered positive attitude, while $<3$ was considered negative attitude.

e) Social class was classified according to Fahmy and his colleagues into high (33.648), medium $(19.2-<33.6)$, and low $(<19.2)$ depending on the score calculated (48).

Administrative Approval: The study approved by the faculty of medicine, Zagazig University. An official permission letter was obtained from the head of the internal medicine department of the faculty of medicine, Zagazig University.

Ethical Approval: Ethical considerations were taken through the whole study including fully informed participants with the purpose and nature of the study and then oral consent was taken from participants. Coded numbers for each participant were used to guarantee privacy. Official approval from the Institutional review board (IRB) was taken (ZU-IRB \#5698).

Data mangement: The collected data were analyzed by computer using Statistical Package of Social Services version 24 (SPSS), Data were represented in tables and graphs, Continuous Quantitative variables e.g. age were expressed as mean $\pm \mathrm{SD} \&$ (range), and categorical qualitative variables were expressed as absolute frequencies (number) \& relative frequencies (percentage), Percentage of change was calculated for change in knowledge, attitude and practice scores after the intervention, it equals the change in value divided by the absolute value of the original value, multiplied by 100 , Suitable statistical tests of significance were 
used after checked for normality using Kolmogorov-Smirnov and Shapiro-Wilk tests. Wilcoxon signed-rank test was used for comparison of paired scores, and Mc Nemar test was used for categorical data, Stepwise linear regression models were used to predict the change in knowledge score post-intervention, the results were considered highly statistically significant when the significant probability was less than $0.001(\mathrm{P}<0.001)$.

\section{Results:}

The current study included 70 diabetic patients, their age ranged from 22-72 years old, $41(58.6 \%)$ of them were males while $29(41.4 \%)$ of them were females, $72.9 \%$ of males were working, while only $41.4 \%$ of females were working, $55.7 \%$ of females were moderately and highly educated vs. $60 \%$ of males. More than half of the studied patients were residents of rural areas $(58.6 \%)$, and only $30 \%$ of them were of high social class, type II diabetes was the commonest among most of them $(81.4 \%)$, about $3 / 4$ of them $(71.4 \%)$ were diagnosed with DM for more than 15 years, DM was accompanied mainly by Hypertension in $(82.9 \%)$ and Dyslipidemia in $(75.7 \%)$.

Prevalence of diabetic retinopathy among the recruited patients was $55.7 \%$, and they were diagnosed with DR after 3- 15 years from DM diagnosis, mean duration of diabetic retinopathy was $8.67 \pm 3.5$ years, most of them had positive DM family history, $62.9 \%$ of the studied group was smokers (Table 1). Patients with good knowledge of retinopathy constituted only $8.6 \%$ of the total studied diabetic patients $(n=70)$, while positive attitude towards retinopathy was found in $35.7 \%$ of the total number of patients in the study, only 3 out of 70 patients $(4.3 \%)$ were had a good practice of diabetic retinopathy, with significantly statistically difference after the intervention, (Figure 1).

The score of knowledge about Diabetes mellitus and diabetic retinopathy significantly increased by $116.58 \%$ from $9.65 \pm 2.45$ to 20.9 \pm 3.26 for DR after health education, $(\mathrm{p}<$ $0.0001 *)$, also there was a significant increase in the positive attitude and good practice after intervention by $45.5 \% \quad \uparrow$ and $230.7 \% \uparrow$ respectively (Table 2). Duration of Diabetic retinopathy significantly correlated with Knowledge toward DR ( $\mathrm{r}=0.567$, p-value $<0.001)$ pre-intervention, while after health education program knowledge scores were positively correlated with attitude and duration of DR, also there was a positive significant correlation between attitude toward DR and Duration of DR $(r=0.340, \mathrm{P}<0.05)$ was shown in (Table 3). Stepwise multiple linear regression models for knowledge score post-intervention, (Table 4) displays that knowledge score and Knowledge plus attitude were statistically significant independent predictors which explained $53.8 \%, 68.4 \%$ of the change in total post-program knowledge, Stepwise multiple linear regression model displaying Knowledge, attitude, practice post-intervention and Duration of DR explained $78.9 \%$ of the change in knowledge score post-intervention. 
The barriers to compliance with periodic eye checkup, financial problems were the commonest barrier among most of them, $42.9 \%$ of the patients did not feel the necessity for an eye checkup as they had good vision, about $1 / 5$ of them did not know that they should go for a periodic eye checkup (21.4\%) (Table 5).

\section{Discussion:}

This was an interventional study, to evaluate the changes in the knowledge, attitude, and practice (KAP) patterns of diabetic patients regarding diabetic retinopathy. The study included 70 diabetic patients attending Zagazig outpatient clinics. Only $(8.6 \%)$ in the study had good knowledge about diabetes. This is contrary to the results of two studies conducted in South India ${ }^{(6,9)}$ which reported a good knowledge of $40.7 \%$ and $42 \%$ respectively of the subjects of their studies. Also, in another study done in South India, $28 \%$ of the population was 'aware' of diabetes. ${ }^{(10)}$

We found that about $1 / 3$ of the studied group had a positive attitude towards diabetic retinopathy $35.7 \%$; this also was reported as $37.1 \%$ in a study done in 2008 among rural populations in India. ${ }^{(11)}$ Good practice patterns concerning DR were found in only (4.3\%) of the studied group; this is unlike a study in Bangladesh, 2017 which reported good practice in $22 \%$. $^{(12)}$ In comparison to a study done in Saudi Arabia ${ }^{(13)}$ which assessed Knowledge, attitude, and practice regarding diabetic retinopathy screening and its management among diabetic patients at a private hospital in
Riyadh on 200 participants from endocrinology unit and the eye clinic and reported an excellent knowledge of the ophthalmic effects of diabetes in $(45.5 \%)$ of participants, $(19 \%)$ of participants had a positive attitude, and poor practice was noted in (74\%) of participants. Likewise, a study was conducted in 2016 $6^{(14)}$ in central Saudi Arabia which revealed a satisfactory knowledge of DR in $64 \%$ and +ve attitude in only $13 \%$ of the participants.

Poor practice in our study may be explained as most of our studied sample were of moderate and low social class (28.6\% and $41.4 \%)$ respectively, facing financial difficulties leading to the presence of barriers for regular eye examination where financial problems were the commonest barrier among most of them, this agrees with a study in Germany ${ }^{(15)}$ which reported that eye care services utilization declined mostly among diabetics with lower socioeconomic status in Germany. Most of the patients $(42.9 \%)$ did not feel the necessity for regular eye checkup as they had good vision, this is concomitant with a study (16) which applied on 209 people in Ireland and found that the main barriers to receive adequate screening for DR were lack of knowledge regarding the need for an ocular examination. About $1 / 5$ of the participants in the current study did not know that they should go for a periodic eye checkup to exclude ocular complications of diabetes, although most diabetic patients seem to know that regular follow up is necessary for diabetes disease, this is similar to Nam et al., 2011 (17) 
who stated that Culture and language capabilities influence the patient's health beliefs, attitudes, also the patient's financial resources, co-morbidities, and social support are important factors affecting patients behavior regarding regular diabetes follow up.

Education for self-care and improving the knowledge is a process with several challenges, especially in the presence of DM, a condition that affects people of all ages, with different levels of schooling and social and environmental bases, Diabetes selfmanagement education and support is needed to help people with diabetes to navigate decisions and activities and has been shown to improve health outcomes and it is the process of facilitating the knowledge, skill, and ability necessary for diabetes self-care. ${ }^{(18)}$

In our study after implementing the health education sessions; knowledge, attitude, and practice to DR significantly increased by $116.58 \%, 45.5 \%$, and $230.7 \%$ respectively. A study assessed the effects of health education on the achievements of diabetic patients regarding control and improvement of their health status in Khartoum State, Sudan ${ }^{(19)}$ and found that diabetic patients gained more knowledge after the implementation of the program, particularly in the areas of the nature and signs and symptoms of the disease.

The Global prevalence of DR among diabetic patients is estimated to be $34.6 \% .^{(20)}$ In the Eastern region of Saudi, $201{ }^{(21)}$ the prevalence of DR was $30 \%$, surprising we found that $55.7 \%$ of our studied sample was suffering from DR. This result was the same in Syria ${ }^{(22)}$ where $59.6 \%$ of diabetic patients reported having an eye problem due to DM but it's not in agreement with a study done in Egypt ${ }^{(23)}$ on 1,325 patients was selected with a mean age of 49 years; DR was found in $20.5 \%$ of patients. Higher duration of Diabetes mellitus, an older mean of age, and the presence of other comorbidities in the form of hypertension and dyslipidemia may be the clue for higher prevalence among our studied sample.

Highlighting the prevalence of DR and the link between DR and diabetes duration are warranted to prompt a reassessment of personal risk. ${ }^{(24)}$ In our study we found that duration of Diabetic retinopathy significantly correlated with knowledge toward DR pre-intervention, while after health education program knowledge scores were positively correlated with attitude and duration of DR, also there was a positive significant correlation between attitude toward DR and Duration of DR. Knowledge refers to the understanding of diabetic retinopathy, an attitude refers to patient's perception, as well as any preconceived ideas they may have and practice refers to the methods in which patients apply their attitudes and behaviors as using of services regarding eye care. ${ }^{(25)}$ In our study Knowledge, attitude, practice post-intervention, and duration of DR explained $78.9 \%$ of the change in knowledge score post-intervention.

Preventive plans should be designed to spread knowledge among diabetic patients and 
the general population regarding ocular complications of diabetes. Doctors may refer patients for screening for diabetic retinopathy, but the continuity of care and better compliance need good communication with patients, in addition to a thorough explanation about diabetes and its complications, especially diabetic retinopathy. ${ }^{(22)}$

Limitations: Some lack of cooperation was found from the participants due to a shortage of time and the clinic crowdedness, but we persuaded them after explaining the importance of the study and implementing the valued patient education.

Conclusion: Patient education and public health education have a great effect on improving patient compliance and self-care. Financial problems, poor family support, lack of knowledge, and interest were common barriers of non-compliance that should be overcome.

Recommendations: Regular patient education sessions focusing on early screening of DR and increasing compliance to follow-up and regular eye examination through primary health care doctors and specialists are the clue for preventing silent blindness.

Acknowledgment: The authors would like to thank the participants of the study.

Fund: The research was conducted with no fund.

Conflict of Interest: There was no conflict of interest.

\section{References:}

1. World Health Organization. Blindness and vision impairment. Tool for assessment of diabetes and diabetic retinopathy; 2015. (accessed August 2019) https://www.who.int/blindness/publication s/TADDS_EN.pdf

2. International Diabetes Federation. IDF Middle East and North Africa region. IDF Diabetes Atlas- $8^{\text {th }}$ edition; 2017. (accessed August 2019) https://www.idf.org/ouractivities/advocacy-awareness/resourcesand-tools/134-idf-diabetes-atlas-8thedition.html

3. Hegazi R, El-Gamal M, Abdel-Hady N, Hamdy O. Epidemiology of and risk factors for type 2 diabetes in Egypt. Annals of global health. 2015 Nov 1;81(6):814-20.

4. Khalaf FR, Fahmy HM, Ibrahim AK, Mohamed GA, Eldeen ME, Elkady A, Hetta HF. Does a diabetic retinopathy educational program raise awareness among elderly diabetic patients?. Diabetes, Metabolic Syndrome and Obesity: Targets and Therapy. 2019;12:1867.

\section{American Diabetes Association.}

Disclosures: Standards of Medical Care in Diabetes-2019. (accessed October 2019) https://care.diabetesjournals.org/content/4 2/Supplement_1

6. Srinivasan NK, John D, Rebekah G, Kujur ES, Paul P, John SS. Diabetes and diabetic retinopathy: knowledge, attitude, practice 
(KAP) among diabetic patients in a tertiary eye care centre. Journal of clinical and diagnostic research: JCDR. 2017 $\mathrm{Jul} ; 11(7)$ :NC01.

7. Geethadevi M, Thampi B, Antony J, Raghavan R, Sasidharan RR, Mohan A. A study of knowledge, attitude and practice in diabetic retinopathy among patients attending a primary health care centre. International Journal of Research in Medical Sciences. 2018 Sep;6(9):3020.

8. Fahmy SI, Nofald LM, Shehatad SF, El Kadyb HM, Ibrahimc HK. Updating indicators for scaling the socioeconomic level of families for health research. $\mathrm{J}$ Egypt Public Health Assoc. 2015; 90:1-7. 9. Hussain R, Rajesh B, Giridhar A, Gopalakrishnan M, Sadasivan S, James J, Vijayan PP, John N. Knowledge and awareness about diabetes mellitus and diabetic retinopathy in suburban population of a South Indian state and its practice among the patients with diabetes mellitus: a population-based study. Indian journal of ophthalmology. 2016 Apr;64(4):272.

10. Babu N, Kim D, Ramchandani B, Sachin T. Diabetes and Diabetic Retinopathy: Knowledge, Attitude, Practice (KAP) Among Paramedical Personnel (PMPS) and Community Members (CMS) In Southern India. AIOC Proceedings. 2009:150-53.

11. Rani PK, Raman R, Subramani S, Perumal G, Kumaramanickavel G, Sharma
T. Knowledge of diabetes and diabetic retinopathy among rural populations in India, and the influence of knowledge of diabetic retinopathy on attitude and practice. Rural and Remote Health 2008; 8: 838.

12. Ahmed KR, Jebunessa F, Hossain S, Chowdhury HA. Ocular knowledge and practice among type 2 diabetic patients in a tertiary care hospital in Bangladesh. BMC ophthalmology. 2017 Dec;17(1):171.

13. Al-Asbali T, Aldawari SA, Alzahim IA, Alalawi H, Khandekar R, Lotfy NM. Knowledge, attitude and practice regarding diabetic retinopathy screening and its management among diabetic patients at a private hospital of Riyadh, Saudi Arabia. Saudi Journal of Ophthalmology. 2019 Dec 31.

14. Al-Alawi A, Al-Hassan A, Chauhan D, AlFutais M, Khandekar R. Knowledge, attitude, and perception of barriers for eye care among diabetic persons registered at Employee Health Department of a Tertiary Eye Hospital of Central Saudi Arabia. Middle East African journal of ophthalmology. 2016 Jan;23(1):71.

15. Baumeister SE, Schomerus G, Andersen RM, Tost F, Markus MR, Völzke H, Jürgens C. Trends of barriers to eye care among adults with diagnosed diabetes in Germany, 1997-2012. Nutrition, Metabolism and Cardiovascular Diseases. 2015 Oct 1;25(10):906-15. 
16. Dervan E, Lillis D, Flynn L, Staines A, O'shea D. Factors that influence the patient uptake of diabetic retinopathy screening. Irish journal of medical science. 2008 Dec 1;177(4):303.

17. Nam S, Chesla C, Stotts NA, Kroon L, Janson SL. Barriers to diabetes management: patient and provider factors. Diabetes research and clinical practice. 2011 Jul 1;93(1):1-9.

18. Powers MA, Bardsley J, Cypress M, Duker P, Funnell MM, Fischl AH, Maryniuk MD, Siminerio L, Vivian E. Diabetes selfmanagement education and support in type 2 diabetes: a joint position statement of the American Diabetes Association, the American Association of Diabetes Educators, and the Academy of Nutrition and Dietetics. The Diabetes Educator. 2017 Feb;43(1):40-53.

19. MakkiAwouda FO, Elmukashfi TA, AlTom SA. Effects of health education of diabetic patient's knowledge at Diabetic Health Centers, Khartoum State, Sudan: 2007-2010. Global journal of health science. 2014 Mar;6(2):221.

20. Yau JW, Rogers SL, Kawasaki R, Lamoureux EL, Kowalski JW, Bek T, Chen SJ, Dekker JM, Fletcher A, Grauslund J, Haffner S. Global prevalence and major risk factors of diabetic retinopathy. Diabetes care. 2012 Mar 1;35(3):556-64.
21. Khan AR, Wiseberg JA, Lateef ZA, Khan SA. Prevalence and determinants of diabetic retinopathy in $\mathrm{Al}$ Hasa region of Saudi Arabia: primary health care centre based cross-sectional survey, 2007-2009. Middle East African journal of ophthalmology. $2010 \mathrm{Jul} ; 17(3): 257$.

22. Hamzeh A, Almhanni G, Aljaber Y, Alhasan R, Alhasan R, Alsamman MI, Alhalabi N, Haddeh Y. Awareness of diabetes and diabetic retinopathy among a group of diabetic patients in main public hospitals in Damascus, Syria during the Syrian crisis. BMC health services research. 2019 Dec 1;19(1):549.

23. Macky TA, Khater N, Al-Zamil MA, El Fishawy H, Soliman MM. Epidemiology of diabetic retinopathy in Egypt: a hospitalbased study. Ophthalmic research. 2011;45(2):73-8.

24. Lake AJ, Browne JL, Abraham C, Tumino D, Hines C, Rees G, Speight J. A tailored intervention to promote uptake of retinal screening among young adults with type 2 diabetes-an intervention mapping approach. BMC health services research. 2018 Dec;18(1):396.

25. Al Zarea BK. Knowledge, attitude and practice of diabetic retinopathy amongst the diabetic patients of AlJouf and Hail Province of Saudi Arabia. Journal of clinical and diagnostic research: JCDR. 2016 May;10(5):NC05. 
Table (1): Basic Socio-demographic and Clinical Characteristics of the Study Group

\begin{tabular}{|c|c|c|}
\hline \multicolumn{2}{|c|}{ Characteristics } & \multirow{2}{*}{$\begin{array}{c}\text { Frequency }(\%) \\
54.2 \pm 13.2 \\
22-72\end{array}$} \\
\hline Age (years) & $\begin{array}{ll}\text { - } & \text { Mean } \pm \text { SD } \\
\text { - } & \text { Range }\end{array}$ & \\
\hline Sex & $\begin{array}{ll}\text { - } & \text { Male } \\
\text { - } & \text { Female }\end{array}$ & $\begin{array}{l}41(58.6 \%) \\
29(41.4 \%)\end{array}$ \\
\hline Residence & $\begin{array}{ll}\text { - } & \text { Rural } \\
\text { - } & \text { Urban }\end{array}$ & $\begin{array}{l}41(58.6 \%) \\
29(41.4 \%)\end{array}$ \\
\hline Occupation & $\begin{array}{ll}\text { - } & \text { Working males } \\
\text { - } & \text { Working females }\end{array}$ & $\begin{array}{l}51(72.9 \%) \\
29(41.4 \%\end{array}$ \\
\hline Education of husband & $\begin{array}{l}\text { - } \text { Illiterate/read and write } \\
\text { - } \text { Primary education } \\
\text { - } \text { Preparatory education } \\
\text { - Secondary education } \\
\text { - } \quad \text { University education } \\
\end{array}$ & $\begin{array}{l}18(25.7 \%) \\
7(10.0 \%) \\
3(4.3 \%) \\
21(30 \%) \\
21(30 \%) \\
\end{array}$ \\
\hline Education of Wife & $\begin{array}{l}\text { - } \text { Illiterate/read and write } \\
\text { - } \text { Primary education } \\
\text { - } \text { Preparatory education } \\
\text { - Secondary education } \\
\text { - } \quad \text { University education } \\
\end{array}$ & $\begin{array}{c}25(37.5 \%) \\
3(4.3 \%) \\
3(4.3 \%) \\
18(25.7 \%) \\
21(30 \%) \\
\end{array}$ \\
\hline Social class & $\begin{array}{ll}\text { - } & \text { Low } \\
\text { - } & \text { Medium } \\
\text { - } & \text { High }\end{array}$ & $\begin{array}{l}29(41.4 \%) \\
20(28.6 \%) \\
21(30.0 \%)\end{array}$ \\
\hline DM type & $\begin{array}{ll}\text { - } & \text { Type I } \\
\text { - } & \text { Type II }\end{array}$ & $\begin{array}{l}13(18.6 \%) \\
57(81.4 \%)\end{array}$ \\
\hline DM Duration & $\begin{array}{l}\text { - } \text { Less than } 5 \text { years } \\
\text { - } 5 \text { - } 10 \text { years } \\
\text { - } \text { More than } 10 \text { years }\end{array}$ & $\begin{array}{c}3(4.3 \%) \\
17(24.3 \%) \\
50(71.4 \%)\end{array}$ \\
\hline Comorbid diseases & $\begin{array}{ll}\text { - } & \text { Hypertension } \\
\text { - } & \text { Dyslipidemia } \\
\text { - } & \text { CVD } \\
\text { - } & \text { Renal Diseases } \\
\end{array}$ & $\begin{array}{l}58(82.9 \%) \\
53(75.7 \%) \\
19(27.1 \%) \\
11(15.7 \%) \\
\end{array}$ \\
\hline Frequency of DR & - Diabetic retinopathy & $39(55.7 \%)$ \\
\hline Duration of DR (years) & $\begin{array}{ll}\text { - } & \text { Mean } \pm \text { SD } \\
\text { - } & \text { Range }\end{array}$ & $\begin{array}{c}8.67 \pm 3.56 \\
3-15\end{array}$ \\
\hline Smokers & & $44(62.9 \%)$ \\
\hline Positive Family history & & $59(84.3 \%)$ \\
\hline
\end{tabular}


Table (2): Mean score of Knowledge, Attitude, and Practice for DR among the Study Group

\begin{tabular}{|l|c|c|c|c|c|}
\hline \multicolumn{2}{|c|}{ Score of KAP } & $\begin{array}{c}\text { Pre- } \\
\text { intervention }\end{array}$ & $\begin{array}{c}\text { Post- } \\
\text { intervention }\end{array}$ & $\begin{array}{c}\text { \% of } \\
\text { change } \neq\end{array}$ & ap-value \\
\hline Knowledge & - Mean \pm SD & $9.65 \pm 2.45$ & $20.9 \pm 3.26$ & $116.58 \% \uparrow$ & $<\mathbf{0 . 0 0 0 1 *}$ \\
for DR & - median (Range) & $10(2-14)$ & $20(14-28)$ & & \\
\hline Attitude & - Mean \pm SD & $2.57 \pm 0.88$ & $3.74 \pm 0.44$ & $45.5 \% \uparrow$ & $<\mathbf{0 . 0 0 0 1 *}$ \\
towards & - median (Range) & $3(1-4)$ & $4(3-4)$ & & \\
DR & - Mean \pm SD & $1.14 \pm 1.09$ & $3.77 \pm 1.14$ & $230.7 \% \uparrow$ & $<\mathbf{0 . 0 0 0 1 *}$ \\
\hline Practice & - median (Range) & $1(0-4)$ & $4(1-5)$ & & \\
for DR & & & & & \\
\hline
\end{tabular}

$\$$ Percentage of change $=($ pre - post $/$ pre $) * 100$,

*statistical significance

${ }^{\text {a }}$ Wilcoxon signed-rank test was used for paired analysis

Table (3): Correlation Matrix for the Score of Knowledge, Attitude and Practice for DR throughout the Program among the Study Group

\begin{tabular}{|c|c|c|c|}
\hline & \multicolumn{3}{|c|}{ Pearson correlation coefficient } \\
\hline & Knowledge & Attitude & Practice \\
\hline $\begin{array}{l}\text { Pre-intervention } \\
\text { - Knowledge score } \\
\text { - Attitude score } \\
\text { - Practice score } \\
\text { - } \text { Duration of DR }\end{array}$ & $\begin{array}{c}1.00 \\
0.200 \\
0.185 \\
0.576 * *\end{array}$ & $\begin{array}{c}1.00 \\
0.249 \\
0.102\end{array}$ & $\begin{array}{c}1.00 \\
0.152\end{array}$ \\
\hline $\begin{array}{l}\text { Post-intervention } \\
\text { - Knowledge score } \\
\text { - Attitude score } \\
\text { - Practice score } \\
\text { - } \text { Duration of DR }\end{array}$ & $\begin{array}{c}1.00 \\
0.277^{*} \\
0.235 \\
0.365^{* *}\end{array}$ & $\begin{array}{c}1.00 \\
0.095 \\
0.340 *\end{array}$ & $\begin{array}{c}1.00 \\
0.193\end{array}$ \\
\hline
\end{tabular}


Table (4): Stepwise Multiple Linear Regression Model for the Total Post-intervention Knowledge Score

\begin{tabular}{|c|c|c|c|c|c|c|}
\hline & \multirow[t]{2}{*}{ Model } & \multirow[t]{2}{*}{$\mathbf{R}^{2}$} & \multicolumn{2}{|c|}{$\begin{array}{c}\text { Unstandardized } \\
\text { Coefficients } \\
\end{array}$} & \multirow[t]{2}{*}{ t-test } & \multirow{2}{*}{$\begin{array}{c}\text { p- } \\
\text { value }\end{array}$} \\
\hline & & & B & Std. Error & & \\
\hline \multirow[t]{2}{*}{1} & - $\quad($ Constant $)$ & \multirow[t]{2}{*}{0.538} & 12.36 & 1.299 & 9.516 & 0.000 \\
\hline & - Knowledge pre-intervention & & .895 & 0.146 & 6.108 & $0.000 *$ \\
\hline \multirow[t]{3}{*}{2} & - (Constant) & \multirow[t]{3}{*}{0.684} & 2.095 & 2.929 & .715 & 0.480 \\
\hline & - Knowledge pre-intervention & & 1.011 & 0.127 & 7.965 & $0.000 *$ \\
\hline & $\begin{array}{l}\text { - Attitude pre-intervention } \\
\text { toward DR }\end{array}$ & & 2.545 & 0.673 & 3.779 & $0.001 *$ \\
\hline \multirow[t]{4}{*}{3} & - (Constant) & \multirow[t]{4}{*}{0.744} & -6.194 & 4.121 & -1.503 & 0.143 \\
\hline & - Knowledge pre-intervention & & 1.033 & 0.116 & 8.872 & $0.000 *$ \\
\hline & $\begin{array}{l}\text { - Attitude pre-intervention } \\
\text { toward DR }\end{array}$ & & 2.002 & 0.649 & 3.083 & $0.004^{*}$ \\
\hline & - Duration of DR & & 3.427 & 1.294 & 2.649 & $0.013^{*}$ \\
\hline \multirow[t]{5}{*}{4} & - (Constant) & \multirow[t]{5}{*}{0.798} & -7.356 & 3.747 & -1.963 & 0.059 \\
\hline & - Knowledge pre-intervention & & 1.173 & 0.117 & 10.061 & $0.000^{*}$ \\
\hline & $\begin{array}{l}\text { - Attitude pre-intervention } \\
\text { toward DR }\end{array}$ & & 1.958 & 0.587 & 3.335 & $0.002 *$ \\
\hline & - Duration & & 3.780 & 1.176 & 3.215 & $0.003 *$ \\
\hline & - Practice pre-intervention & & -.807 & 0.290 & -2.783 & $0.009 *$ \\
\hline
\end{tabular}

*significant

Table (5): Barriers to Compliance with Regular Followup and Periodic Eye Checkup among the Study Group

\begin{tabular}{|c|c|}
\hline \multicolumn{1}{|c|}{ †Barriers } & Frequency (\%) \\
\hline Barriers to compliance with periodic eye checkup: & \\
\hline - Poor family support & $38(54.3 \%)$ \\
\hline - Long-distance to hospital & $22(31.4 \%)$ \\
\hline - Financial problems & $65(92.9 \%)$ \\
\hline - Physically unwell & $30(42.9 \%)$ \\
\hline - Had good vision; did not feel the need for a checkup & $15(21.4 \%)$ \\
\hline
\end{tabular}

† Multiple barriers were found 


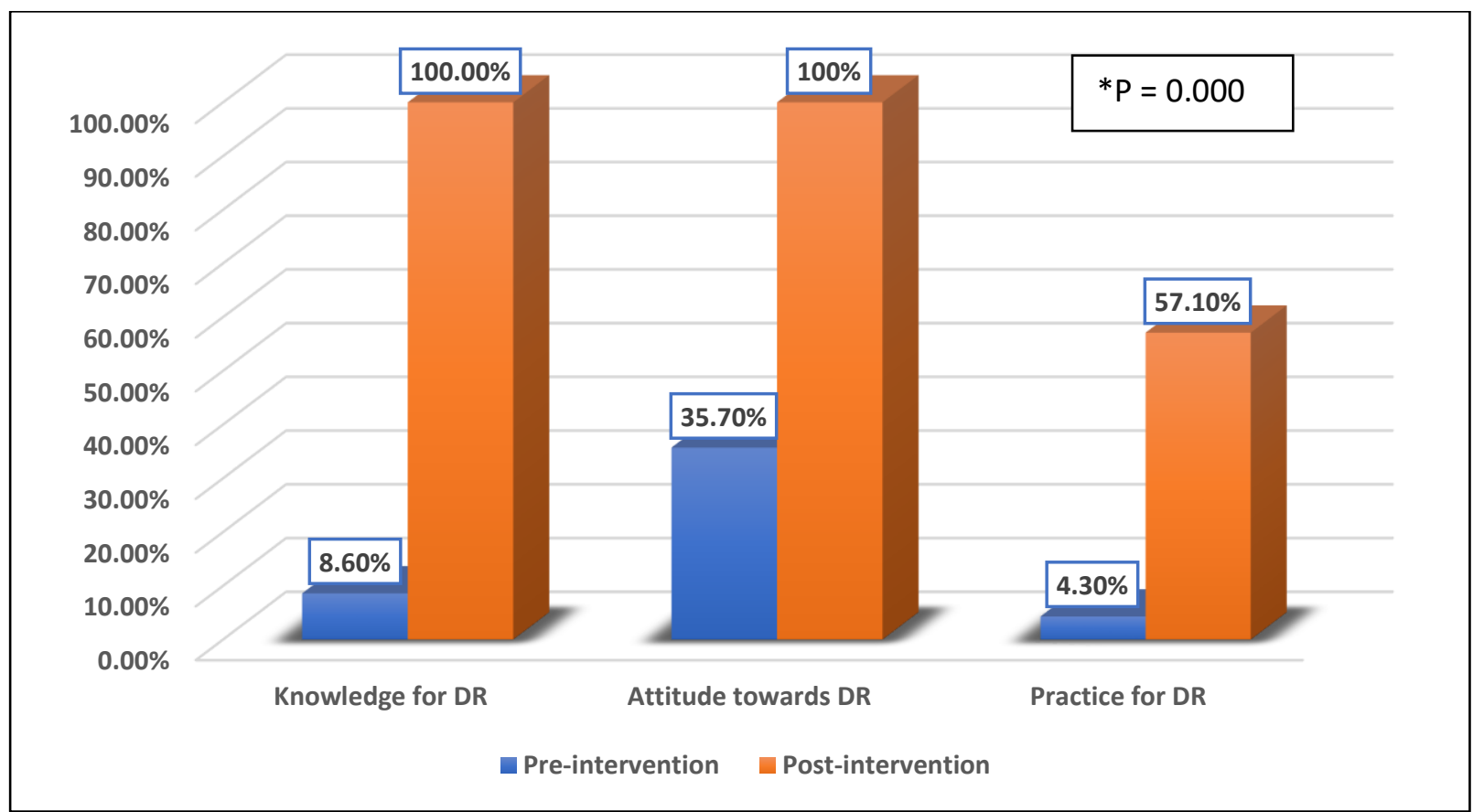

Figure (1): Satisfactory Knowledge, Attitude, and Practice for DR among the Study Group *Mc Nemar test

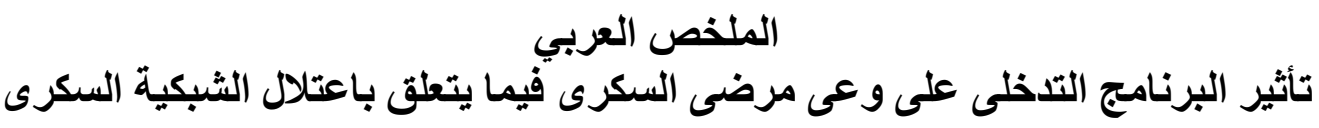

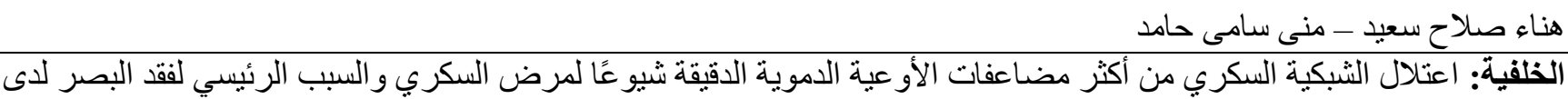

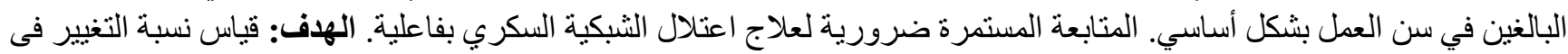

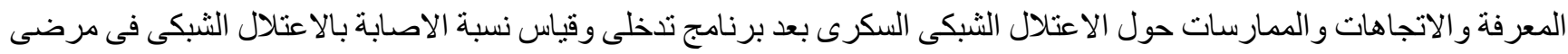

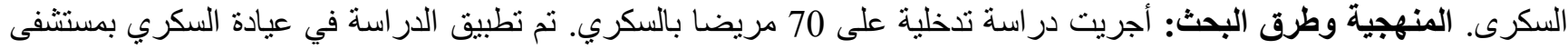

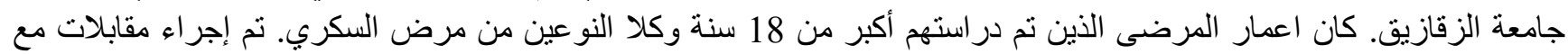

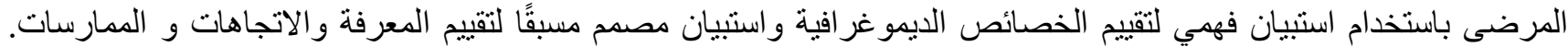

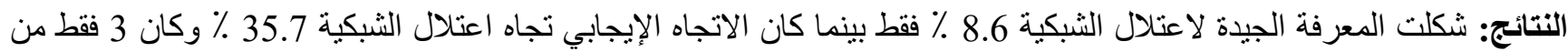

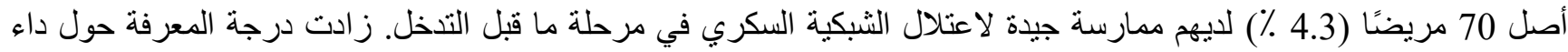
السكري واعتلال الثبكية السكري بشكل ملحوظ بنسبة 116.58٪ بعد التنقيف الصحي ، كما كانت هناك زيادة كبيرة في نسبة الاتجاه

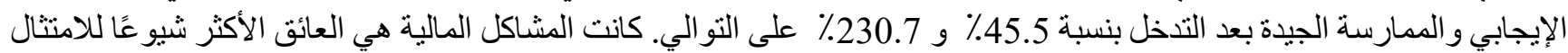

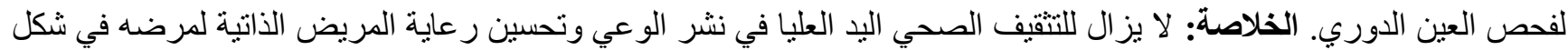

اتجاهات إيجابية وممارسات جيدة. 